\title{
Transient DC Over-Voltage Protection for ITER PF AC/DC Converter
}

\author{
Xiaojiao CHEN, Liansheng HUANG, Shiying HE, Ying ZUO, Jinlin CHEN, and Yang CHEN
}

\begin{abstract}
The International Thermonuclear Experimental Reactor (ITER) poloidal field (PF) AC/DC converters are composed by thyristor-based phase controlled converter modules. As the core component of ITER PF AC/DC converter, the thyristor is very sensitive to over-voltage and damaged in microseconds, therefore, the transient over-voltage protection strategy is desperately essential to ensure the converter safety operation. In this paper, a nanosecond respond and high reliability protection strategy which combined by Metal Oxide Varistor (MOV) and external bypass is proposed to protect the ITER PF AC/DC converter from transient DC over-voltage. The MOV is designed to certify the fast respond in nanosecond. Moreover, a bidirectional BreakOver Diode (BOD) circuit board is designed to activate external bypass to ensure the reliability of the transient DC over-voltage protection strategy. The performance-testing platform is built to study its performance. The experiments on ITER PF AC/DC converter test facility are carried out. According to the experiment results, the external bypass is triggered by BOD board effectively and the load current is transferred to the external bypass in 2 us when BOD suffers from an over-voltage. The effectiveness of the proposed transient DC over-voltage protection strategy is verified.
\end{abstract}

Index Terms-BOD, ITER PF AC/DC converter, transient DC overvoltage protection, MOV.

\section{INTRODUCTION}

$\mathrm{I}$ NTERNATIONAL Thermonuclear Experimental Reactor (ITER) is an international nuclear fusion research and engineering project to demonstrate the feasibility of fusion power for peaceful uses. The poloidal field (PF) AC/DC converter system is one of the key systems for ITER equipment which is responsible to provide the controlled current to excite plasma and adjust the plasma position [1].

Six PF superconducting coils (PF1 to PF6) are embedded in the ITER equipment and fed by 16 sets of converter units. According to the design requirements, the superconducting coils PF2 to PF5 are respectively supplied by ITER PF AC/DC in

Manuscript received October 30, 2020; revised February 6, 2021; accepted April 12, 2021. Date of publication December 30, 2021; date of current version December 17, 2021. (Corresponding author: Shiying He.)

X. Chen, S. He, and Y. Zuo are with Institute of Plasma Physics, Chinese Academy of Sciences, Hefei, China (e-mail: shyinghe@ipp.ac.cn).

L. Huang is with Institute of Plasma Physics, Chinese Academy of Sciences and University of Science and Technology of China, Hefei, China.

J. Chen is with State Grid Jiangsu Electric Power Engineering Consulting Co., Ltd, Nanjing, China.

Y. Chen is with State Grid Rizhao Power Supply Company, Rizhao, China.

Digital Object Identifier 10.24295/CPSSTPEA.2021.00026

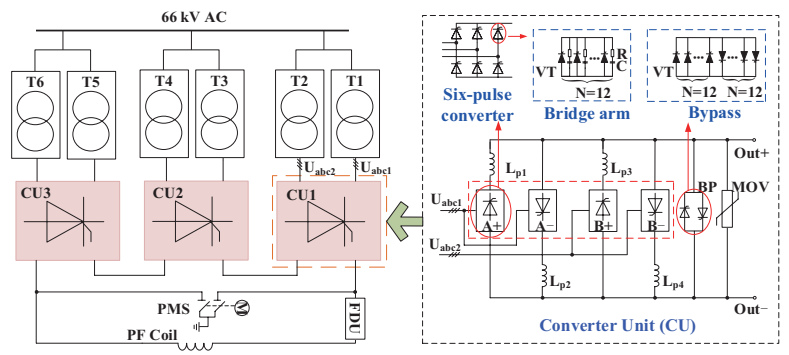

Fig. 1. Topology of the ITER PF AC/DC in series converters.

series converters as Fig. 1 while the PF1 and PF6 are supplied by one unit [2]. In Fig. 1, the T1 to T6 are the converter transformers, the CU1 to CU3 are the converter units. $\mathrm{U}_{\mathrm{abcl}}$ and $\mathrm{U}_{\mathrm{abc} 2}$ are the AC voltage on the secondary side of the converter transformer. $\mathrm{L}_{\mathrm{p} 1}$ to $\mathrm{L}_{\mathrm{p} 4}$ are the $\mathrm{DC}$ reactors. $\mathrm{BP}$ is the external bypass. The converter unit is designed to produce $\mathrm{DC}$ voltage and $\mathrm{DC}$ current rated for $\pm 1.05 \mathrm{kV} / \pm 55 \mathrm{kA}$ which can implement four-quadrant operation with three operation modes [3].

As the core component of ITER PF AC/DC converter, the thyristor is very sensitive to over-voltage. As the core component of the converter, the thyristor will be damaged in milliseconds by over-voltage, therefore, the transient over-voltage research for ITER PF AC/DC converter and its protection strategy is desperately essential to ensure the converter safety operation.

The transient over-voltage and its protection has been widely studied in power system, and lots of achievements have been obtained [4]-[6]. However, with the characteristic that high power, complex operating mode and large purely inductive load, the transient over-voltage in high power converter system such as ITER PF AC/DC converter has been rarely analyzed. Only the commutating over-voltage protection for ITER PF $\mathrm{AC} / \mathrm{DC}$ converter has been studied by [7]. In this paper, the transient DC over-voltage of ITER PF AC/DC converter caused by plasma disruption and its protection strategy will be presented in detail.

The paper is organized as follows: The transient DC over-voltage that caused by plasma disruption and the design requirements of its protection is introduced briefly in Section II. Section III provide the transient DC over-voltage protection strategy. In this part, a bidirectional BOD circuit board is also designed to activate the external bypass, which is tested on performance-testing platform. In Section IV, an experimental setup is implemented to validate the effective performance of the proposed protection strategy. Then the conclusion is drawn in Section V. 
TABLE I

The Inductance Value of PF Coils and Peak Value of Induced Voltage

\begin{tabular}{lcc}
\hline \hline Coil & Inductance & The peak value of induced voltage \\
\hline PF1 & $0.7 \mathrm{H}$ & $-4.77 \mathrm{kV}$ \\
PF2 & $0.47 \mathrm{H}$ & $-7.43 \mathrm{kV}$ \\
PF3 & $1.85 \mathrm{H}$ & $-20.87 \mathrm{kV}$ \\
PF4 & $1.55 \mathrm{H}$ & $-18.06 \mathrm{kV}$ \\
PF5 & $1.55 \mathrm{H}$ & $-10.25 \mathrm{kV}$ \\
PF6 & $2.38 \mathrm{H}$ & $-6.50 \mathrm{kV}$ \\
\hline \hline
\end{tabular}

\section{The Study on DC Over-Voltage}

Ensuring the safe and reliable operation of the ITER PF $\mathrm{AC} / \mathrm{DC}$ converter, one urgent concern is related to the potential over-voltage such as lightning over-voltage, switching over-voltage, commutating over-voltage, transient plasma disruption voltage.

The lightning over-voltage and switching over-voltage are introduced from the AC side of ITER PF AC/DC converter, the analysis of which can take the example of the power system. The commutating over-voltage of ITER PF AC/DC converter has been analyzed in [7]. The transient coupling DC over-voltage that is caused by plasma disruption will be discussed in this paper.

The potential risk of over voltage arisen by the plasma disruption will destroy the converters if the converter fails to keep the suitable conducting path. The voltages are computed by imposing constant current in all PF coils while simulating the plasma disruption. The resulting value represents the plasma-induced component of the voltage that would arise in case of accidental opening of the coil circuits during a disruption. The inductance value of PF coils and the peak value of induced voltage caused by plasma disruption are provided by ITER technical documents shown as Table I.

There are three design requirements that the protection strategy have to obey thereby guaranteeing the safety of system when the over-voltage occur.

First of all, a short response time for over-voltage protection is the prime concern because the thyristor will be destroyed in microseconds. Since the large purely inductive load stores huge energy, a complete energy release circuit with high power is very essential. The last but not least, the power of the system is very huge, and consequently, the reliability of the protection need to be fully considered.

\section{DC Over-Voltage Protection Strategy}

A two-stage protection strategy is developed combining the advantage of MOV and external bypass as Fig. 2. The MOV is connected in parallel with ITER PF AC/DC converter to guarantee the voltage within tolerable insulation levels and ensure the fast over-voltage protection during faults. However, the MOV can't absorb the huge energy in PF coil. Considering the MOV's characteristics [8], the MOV device is designed as a time buffer for external bypass. The external bypass is designed to withstand the load current long time when the DC terminal suffers the transient over-voltage. The protection operates in two stages:

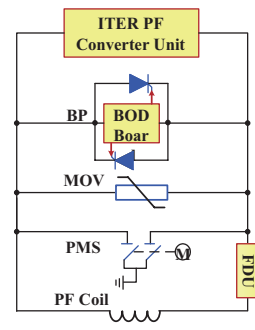

(a)

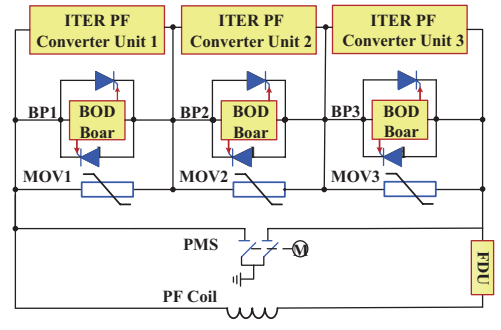

(b)
Fig. 2. The protection scheme for ITER PF AC/DC converter. (a) For PF1 and PF6. (b) For PF2-PF5.

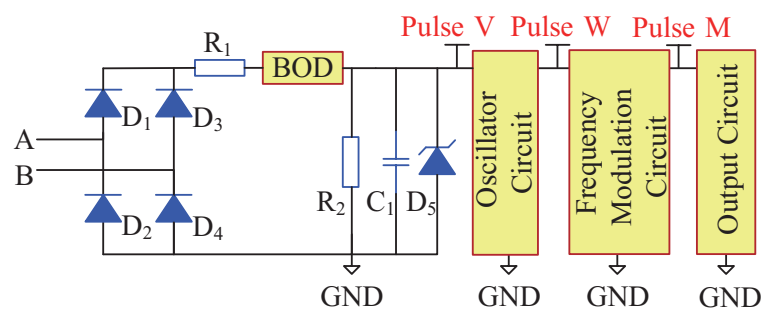

Fig. 3. The bidirectional BOD circuit scheme.

\section{A. Bidirectional BOD Circuit}

The external bypass provides the protection of ITER PF converter and PF coils in fault conditions. During DC over-voltage protection, the main function of bypass is to bypass the current in MOV device. The structure of bypass is designed with bidirectional bridge arms to withstand $\pm 350 \mathrm{kA}$ over-current within $80 \mathrm{~ms}$ and each bridge arm contains 12 thyristors in parallel to withstand huge over-current [9]. The model of the thyristor in external bypass is KPD 5000-52.

The BOD is indispensable for the thyristor over-voltage protection in many cases [10], [11], especially when the load conditions are unpredictable. Therefore, the BOD is used to trigger the external bypass in ITER PF AC/DC converter. In order to activate these thyristors reliably when bypass suffers an over-voltage, a bidirectional BOD circuit is presented to provide the combined functions of over-voltage bidirectional detection and reliable firing performance of the external bypass.

\section{1) The Bidirectional BOD Circuit Scheme}

In external bypass, the over-voltage detection is achieved by connecting BOD between the bypass terminal in such a way that it can turn on when excessive break-over voltage occurs. Then the BOD starts conducting with a low voltage, until its minimum holding current reached. The reliable firing performance and the quick-response ability for external bypass is the core for DC over-voltage protection, which can be implemented by bidirectional BOD circuit board. The bidirectional BOD circuit scheme is shown as Fig. 3.

The over-voltage bidirectional detection of this circuit is implemented by a diode $\mathrm{H}$ bridge $\left(\mathrm{D}_{1}-\mathrm{D}_{4}\right)$, current-limiting resistance $\mathrm{R}_{1}, \mathrm{BOD}$ and a sampling circuit. The diode $\mathrm{H}$ bridge $\left(D_{1}-D_{4}\right)$ is chosen to converter the bidirectional input voltage that between $\mathrm{A}$ and $\mathrm{B}$ points into one direction for BOD detec- 


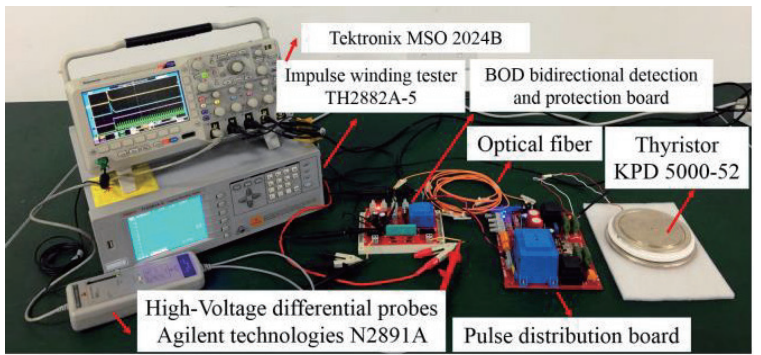

Fig. 4. The performance-testing platform.

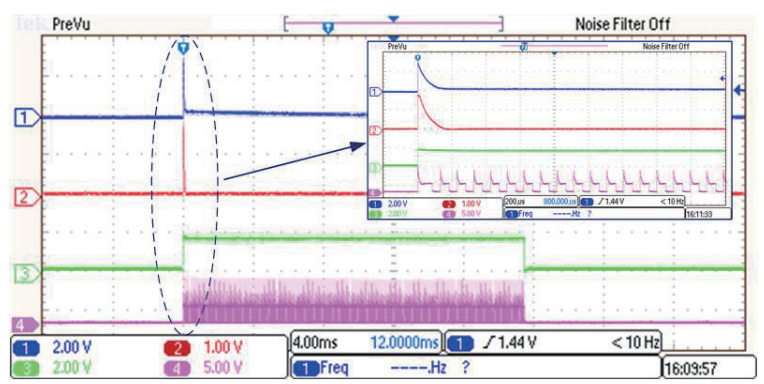

Fig. 5. The experimental results of the firing pulses.

tion. The sampling circuit is consisted by $R_{2}$, capacitance $C_{1}$, voltage-regulator diode $\mathrm{D}_{5}$.

A train of pulse signal is utilized as firing pulse for external bypass instead of a single over-voltage input signal to enhance the reliability. The over-voltage input signal generated by BOD will be widen, modulated and converted into a train of optical signals. Then the pulse distribution board convert it into electric signals for thyristors activating. The output signal Pulse $\mathrm{V}$ in Fig. 3 is a narrow pulse signal, and an oscillator circuit is used to wide it. Nevertheless, the widened pulse Pulse W can't activate the 12 parallel thyristors of external bypass confidently. The frequency modulation circuit is designed to modulate the Pulse W thereby producing a train of reliable firing pulse (Pulse M).

\section{2) The Testing Results of Bidirectional BOD Circuit Board}

Fig. 4 shows the performance-testing platform for bidirectional BOD circuit board. The location of the important waveforms that Pulse V, Pulse W and Pulse M are sketched in the circuit as Fig. 3 and the experimental results are shown in Fig. 5. In this experiment, the bidirectional detection and reliable firing performance is demonstrated.

The quick-response ability of external bypass depends on the turn on time of thyristor and the response time of BOD board. Taking the maximum margin into account, the external bypass response time should be less than 20 us by considering the turnon time of thyristors and the time of BOD board driving should be less than 5 us. The response time of the bidirectional BOD circuit board is less than 2 us by experiment as Fig. 6. In Fig. 5 and Fig. 6, the channel 1 shows the over-voltage signal and the channel 2, 3, 4 show the Pulse V, Pulse W, Pulse M, respectively.

\section{B. MOV Selection}

The internal characteristic of MOV device enables it to act as an

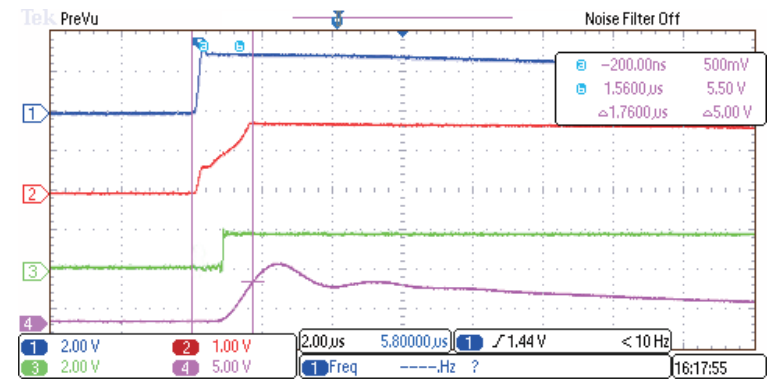

Fig. 6. The response time of bidirectional BOD circuit board.

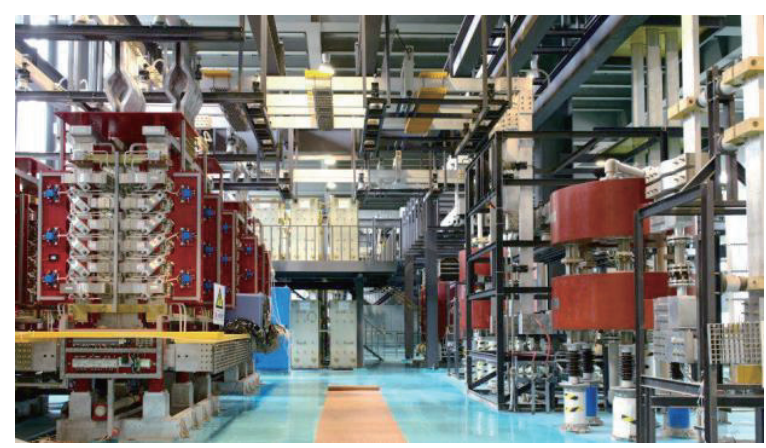

Fig. 7. ITER PF AC/DC converter test facility.

open-circuit when the voltage across the MOV device is below the threshold voltage; but as the voltage exceeds the maximum operating threshold, the MOV impedance diminishes abruptly and allows the current to flow, thus reducing the transient over-voltages. On account of the excellent nonlinear characteristics and the capability of carrying a large amount of electrical current, MOV is widely utilized in electric power equipment to dissipate transient over-voltage and shunt surge current [12].

According to the parameters of ITER PF AC/DC converter, the maximum DC output voltage is $1485 \mathrm{~V}$ and which is also the operating voltage for MOV. The DC breakdown voltage of MOV (UMOV) shall be higher than the breakdown voltage of BOD (UBOD) and the peak value of DC output voltage is $1700 \mathrm{~V}$. Finally, the $3000 \mathrm{~V}$ breakdown voltage of MOV is selected and the mode of MOV is CSP3000FD3P4.

\section{EXPERIMENT}

The ITER PF AC/DC converter test facility is designed and built by Institute of Plasma Physics, Chinese Academy of Science (ASIPP) to complete the integrated performance test for the ITER PF AC/DC converter. The load for ITER PF AC/ $\mathrm{DC}$ converter test facility is dummy load instead of the real $\mathrm{PF}$ coils, therefore the verification of DC over-voltage protection strategy for DC over-voltage caused by plasma disruption is out of condition. In order to prove the effectiveness of the over-voltage protection strategy, the impulse winding tester TH2882A-5 is utilized to produce the DC over-voltage for BOD thereby simulating the DC over-voltage. Fig. 7 shows the ITER PF AC/DC converter test facility. 


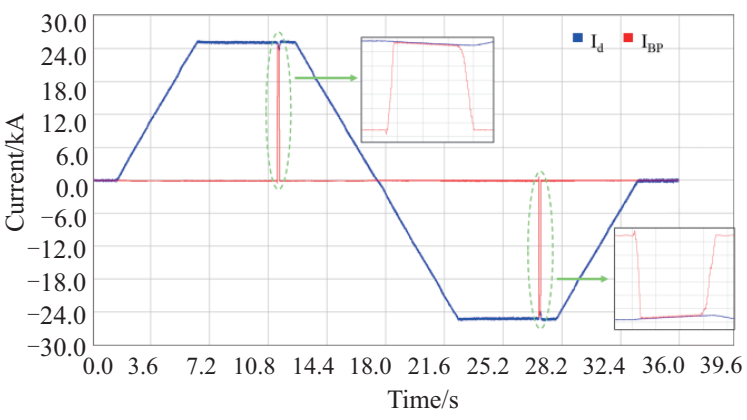

Fig. 8. The external bypass current transfer experiment result.

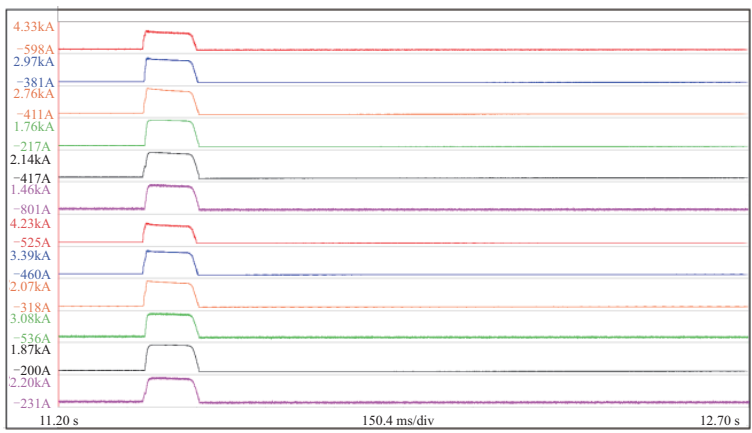

Fig. 9. Current on forward bridge arms of external bypass.

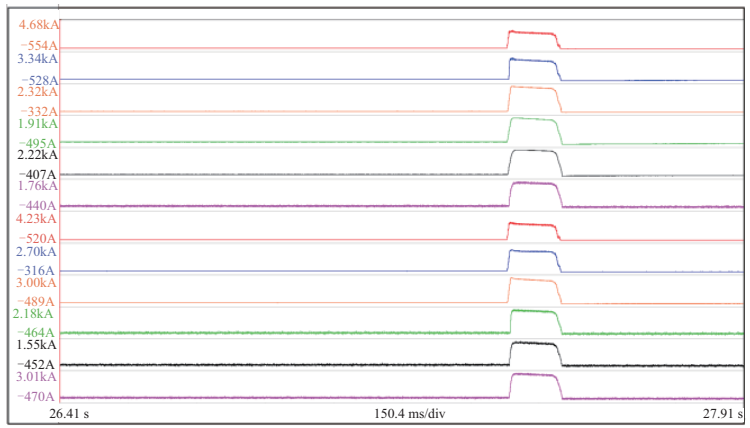

Fig. 10. Current on reverse bridge arms of external bypass.

The bypass is designed with bidirectional bridge arms to withstand positive and negative load currents. To ensure the reliability of external bypass current transfer, the bidirectional bridge arms of external bypass are triggered at the same time to provide a quick path for discharging the energy, whose current direction is.

The external bypass current transfer experiment result is shown as Fig. 8. The $I_{d}$ is the load current and the $I_{B P}$ is the current on external bypass. The external bypass is activated by bidirectional BOD circuit board when the load current is positive or negative respectively. In this experiment, the external bypass is successfully triggered by bidirectional BOD board and the load current is transferred to bidirectional bypass in time. The current on bidirectional bypass forward and reverse bridge arms when bidirectional bypass is triggered is shown as Fig. 9 and Fig. 10. The 12 paralleled bridge arms are conducted at the same time. Finally, the performance of the bidirectional BOD circuit board is proved.

\section{CONCLUSION}

In this paper, a two-stage DC over-voltage protection strategy is developed based on the characteristic analysis of ITER $\mathrm{PF}$ AC/DC converter which gathers the advantages of MOV device and external bypass. The implementation method of the proposed DC over-voltage protection strategy is also presented in detail. In this protection strategy, the BOD is utilized as the pulse generator to implement the protection function of external bypass. In order to provide the functions of over-voltage bidirectional detection and reliable firing performance of external bypass, a bidirectional BOD circuit board is designed and tested on the performance-testing platform. Then the experiment on ITER PF AC/DC converter test facility is carried out. The experiment result shows that the external bypass is triggered by BOD board within 2 us when BOD suffers an over-voltage. The performance of the proposed protection strategy is verified.

\section{ACKNOWLEDGMENT}

The authors would like to thank all the members of ASIPP ITER AC/DC converter team and the colleagues in ITER IO for their hard work.

\section{REFERENCES}

[1] P. Fu, G. Gao, Z. Q. Song, L. W. Xu, L. S. Huang, L. Jiang, J. C. Li, F. W. Zha, L. Dong, and M. Wang, "Preliminary design of the poloidal field AC/DC converter system for the ITER coil power supply," in Fusionence \& Technology, vol. 64, no. 4, pp. 741-747, Nov. 2013.

[2] X. J. Chen, P. Fu, L. S. Huang, G. Gao, and R. J. Fan, "The sequential control of ITER PF in series converters," in Fusion Engineering \& Design, vol. 129, pp. 171-178, Apr. 2018.

[3] P. Fu, G. Gao, L. W. Xu, Z. Q. Song, Z. C. Sheng, J. S. Oh, I. Benfatto, J. Tao, A. D. Mankani, and C. Neumeyer, "Review and analysis of the AC/DC converter of ITER coil power supply," in Proccedings of 2010 Twenty-Fifth Annual IEEE Applied Power Electronics Conference and Exposition (APEC), Palm Springs, CA, USA, Feb. 2010, pp. 1810-1816.

[4] O. D. Adeuyi, M. C. Mane, J. Liang, L. Livermore, and Q. Mu, "Preventing DC over-voltage in multi-terminal HVDC transmission", in CSEE Journal of Power and Energy Systems, vol. 1, no. 1, pp. 86-94, Mar. 2015.

[5] H. T. Yang, Y. T. Chen, J. T. Liao, and C. T. Yang, "Over-voltage mitigation control strategies for distribution system with high PV penetration," in Proccedings of 2015 18th International Conference on Intelligent System Application to Power Systems (ISAP), Porto, Portugal, Sept. 2015, pp. 1-6.

[6] L. M. Qaisieh and H. W. Marar, "Transient over-voltage protection in distributed generators systems," in Proccedings of 2016 IEEE Smart Energy Grid Engineering (SEGE), Oshawa, ON, Canada, Aug. 2016, pp. $1-5$.

[7] F. W. Zha, Z. Q. Song, P. Fu, L. Dong, and M. Wang, "Research on commutating over-voltage protection for ITER poloidal field converter," in IEEE Transactions on Plasma Science, vol. 41, no. 5, pp. 1594-1599, May 2013.

[8] Y. F. Wen and C. K. Zhou, "A novel method for predicting the lifetime of MOV," in IEEE Transactions On Power Delivery, vol. 19 no. 4, pp. 1688-1691, Oct. 2004.

[9] P. Wang, Z. Q. Song, P. Fu, J. C. Li, C. Li, L. Dong, M. Wang, and T. Fan, "Current sharing analysis of external bypass for ITER poloidal field converter," in Journal of Fusion Energy, vol. 34, no. 5, pp. 225-231, Apr. 2015.

[10] J. Zhang, R. Ding, and H. T. Song, "A new reliable supplied gate drive circuit for SCRs with breakover diodes for protection," in Proccedings of 2004 IEEE International Symposium on Circuits and Systems (IEEE Cat. No.04CH37512), Vancouver, BC, Canada, May 2004.

[11] M. S. Hamad, A. K. Abdelsalam, and B. W. Williams, "Over-voltage 
protection of single phase grid connected current source inverters using a simplified passive network," in Proceedings of IET Conference on Renewable Power Generation (RPG 2011), Edinburgh, Sept. 2011.

[12] O. V. Sivov, H. A. Abdelsalam, and E. B. Makram, "Operation of MOV-protected series compensator with wind power during faults," in Proccedings of 2015 North American Power Symposium (NAPS), Charlotte, NC, USA, Oct. 2015.

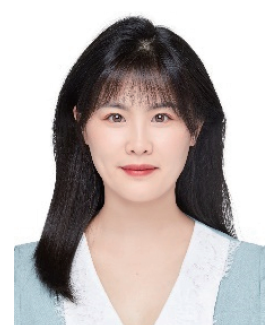

Xiaojiao Chen was born in Anhui, China. She received the Ph.D. degree in nuclear science and engineering from the University of Science and Technology of China, Hefei, China, in 2017.

She is currently an Assistant Researcher with the Institute of Plasma Physics, Chinese Academy of Science.

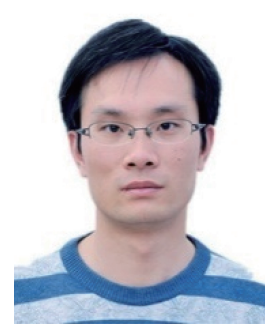

Liansheng Huang was born in Jiangxi, China. He received the Ph.D. degree in nuclear science and engineering from the Chinese Academy of Sciences, Hefei, China, in 2010.

He is currently a Professor with the International Thermonuclear Experimental Reactor Project, Institute of Plasma Physics, Chinese Academy of Sciences.

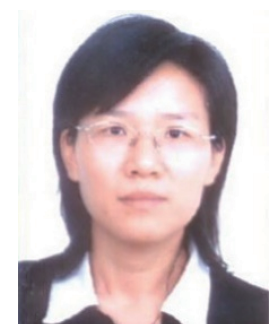

Shiying He was born in Anhui, China, in 1972. She received the B.S. degree in automation from the University of Shanghai for Science and Technology, Shanghai, China, in 1994

She is currently a Senior Engineer with the International Thermonuclear Experimental Reactor Project, Institute of Plasma Physics, Chinese Academy of Sciences, Hefei, China.

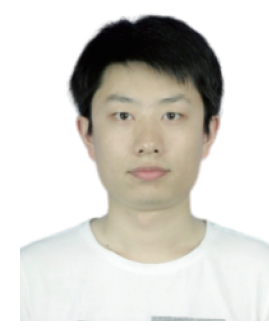

Ying Zuo was born in Anhui, China, in 1991. He received the B.S. degree in electrical engineering and automation from the Hefei University of Technology, Hefei, China, in 2018

$\mathrm{He}$ is currently an Engineer with the International Thermonuclear Experimental Reactor Project, Institute of Plasma Physics, Chinese Academy of Sciences, Hefei, China.

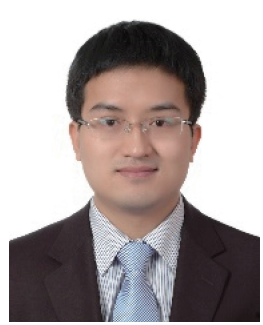

Jinlin Chen was born in Hubei, China, in 1987. He received the M.A. degree in new technology of power electronics from the Institute of Plasma Physics, Chinese Academy of Science, Hefei, China, in 2013.

$\mathrm{He}$ is currently a Senior Engineer with the State Grid Jiangsu Electric Power Engineering Consulting Co., Ltd, Nanjing, China.

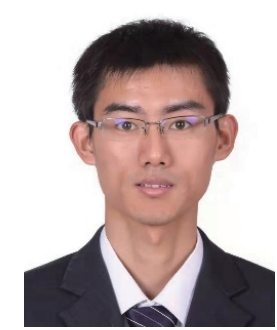

Yang Chen was born in Shandong, China, in 1986. He received the M.A. degree in power electronics and power drives from the Hefei University of Technology, Hefei, China, in 2013.

$\mathrm{He}$ is currently a Senior Engineer with the State Grid Rizhao Power Supply Company, Rizhao, China. 